\title{
Refugee Student Integration: A Focus on Settlement, Education, and Psychosocial Support
}

\author{
Jan Stewart \\ University of Winnipeg \\ Ja.stewart@uwinnipeg.ca \\ Dania El Chaar \\ University of Calgary \\ delchaar@ucalgary.ca \\ Kari McCluskey \\ University of Winnipeg \\ Ka.mc.cluskey@uwinnipeg.ca \\ Kirby Borgardt \\ University of Manitoba \\ borgardk@myumanitoba.ca
}

\begin{abstract}
This research focused on understanding the integration and settlement of Syrian children and youth in Winnipeg and Calgary. The goals were to understand how communities and schools might better support integration, the unique psychosocial and academic needs of Syrian refugees, and how schools can support reciprocal learning among refugee, immigrant, and Canadian-born students. Findings revealed that many refugees experience triple trauma as a result of forced migration, having experienced trauma in their country of origin, during transition, and again upon resettlement in Canada. Further challenges included difficulties in acquiring a new language, interrupted schooling, lack of resources for teachers who felt unprepared for the complexities of student needs, and racism and discrimination experienced by youth trying to integrate with their Canadian peers. The project reveals many gaps in programs and services and highlights the need for a coordinated approach among the different stakeholders in the refugee settlement and integration process.
\end{abstract}

\section{Introduction}

We are living in unprecedented times with over 65.6 million people displaced from their homes because of conflict, persecution, and human rights violations with little evidence that this trend will change (UNHCR, 2017). This marks the highest number of displaced people since World War II. The current situation is often referred to as a "refugee crisis" calling for an immediate and unified global response. World leaders must now grapple with how they will respond, and society must decide whether they will welcome or turn away-build walls or open doors. Of this displaced population, 22.5 million are classified as refugees forced to leave their home country 
and more than half of these are children. Refugee children and their families are a key focus for resettlement efforts. Concentrated support and attention in terms of education, health care, and language learning are essential for successful integration.

Syria, also referred to as the Syrian Arab Republic, has entered its seventh year of conflict resulting in the deaths of over 400,000 citizens and the forcible displacement of twelve million people -including 5.5 million refugees (Human Rights Watch, 2017; UNHCR, 2017). Syria's situation, as with other countries experiencing protracted conflict, has resulted in the massive displacement of people throughout the world. Syrians represent the largest displaced population of present day and the biggest refugee crisis in history. Human Rights Watch (2017) reports that 4.8 million Syrians have sought refuge abroad. These numbers exacerbate the preexisting resettlement demands from other source countries including, South Sudan, Eritrea, Afghanistan, Iraq, Somalia, Libya, Nigeria, Yemen, Democratic Republic of Congo, and the Central African Republic (Amnesty International, 2015; Amnesty International, 2016; UNHCR, 2016). Some European countries have closed their borders, while others have fast-tracked the resettlement of hundreds of thousands of people. As individuals seek refuge in neighbouring countries, these states are at risk of economic collapse (Amnesty International, 2015; Lahav, 2016). Currently, $86 \%$ of the displaced population, nearly 12 million people, are residing in just ten countries in the Global South (Amnesty International, 2015; Amnesty International, 2016).

In recent years, Canada has once again emerged as a prominent player in humanitarian efforts to assist with the resettlement of some of the world's most vulnerable people. Having said this, critics are quick to note that the response was largely due to media attention surrounding the tragic story of Alan Kurdi and the emotional reaction to a situation that appealed to Canadian hearts and the desire to help. While largely a political response that had many unintended consequences, this large-scale major resettlement effort reinforced the Government of Canada's commitment to humanitarian efforts and an opportunity for Canadians to join together to welcome and support its newest citizens. Between January 2015 and December 2017, 93,725 Syrians arrived in Canada including 6,525 Blended Sponsorship Refugees, 41,935 Government Assisted Refugees, and 45, 265 Privately Sponsored Refugees. A total of 7,425 Syrians settled in Manitoba while 12,590 settled in Alberta. From these numbers over 6,000 (about one third) were children and youth under the age of 17 (IRCC, 2017a; IRCC, 2017b).

The rapid response to settle refugees in Canada has had a profound effect on communities, schools, and social service agencies. With many of the arrivals being concentrated over a period of weeks in the winter of 2016, welcoming capacity efforts were ramped up to meet the demands (Rose \& Charette, 2017) and school systems needed to quickly prepare for the large number of Syrian refugee children entering K-12 classrooms.

The higher numbers of refugees arriving within a more condensed time period resulted in particular issues and challenges for schools, settlement organizations, and newcomer serving agencies. The significant increase in the number of new arrivals meant that newcomers were being settled in communities where there typically had not been refugees (or there have been relatively few) before. Lack of housing, difficulties tracking families and connecting them to services, and minimal preparation for the educational system, led to an urgent call for action, Journal of Contemporary Issues in Education, 2019, 14(1), pp. 55-70. 
knowledge mobilization, and creative programming. Federal and provincial governments sent out calls for proposals for evidence-based practices and research to assist with settlement and integration efforts.

This paper discusses the findings of a SSHRC Targeted Research Grants Program focusing on Syrian refugee arrival, resettlement, and integration. Our research program examined the integration and settlement of Syrian children and youth in Winnipeg and Calgary to understand the challenges and/or issues for these children and their families. The research program answered the following overarching questions: (1) How can the school and community best support the integration of Syrian refugees? (2) What are the unique educational and psychosocial needs of children and youth who have recently arrived from Syria? (3) How do schools support reciprocal learning between refugee, immigrant and Canadian-born students? With contributions from youth and relevant stakeholders and through the use of individual interviews and an ongoing youth advisory group, the research has led to more informed recommendations for policy and practice.

\section{Background on the Conflict in Syria}

The historical context of Syria's conflict is essential to understanding the experiences of children and youth and for supporting their long term mental health and wellness. Long before the outbreak of war, Syrians experienced high unemployment, corruption, and lack of freedom due to the repressive regime of President Bashar al-Assad (BBC, 2017). In early 2011, as the Arab Spring spread across the Middle East and North Africa, a group of boys sprayed anti-government graffiti onto the wall of their school in support of the Arab Spring (Al Jazeera, 2017a). Discovery of the graffiti, led police to arrest the 15 boys suspected, detaining and torturing them for weeks (Al Jazeera, 2017a). One of the boys, 13-year-old Hamza al-Khateeb, was killed after being brutally tortured (Al Jazeera, 2017b). These events led to outrage in the country and peaceful protests to demand change.

Protests were met with deadly force from the Assad regime which responded by killing hundreds of demonstrators and imprisoning hundreds more (Al Jazeera, 2017b). As unrest spread and the crackdown intensified, protesters took up arms against the government and defectors from the Syrian Army formed the Free Syrian Army (FSM), a rebel group aimed at overthrowing the government (Al Jazeera, 2017b; BBC, 2017). The country fell into civil war and the conflict has become increasingly more complex as rebel forces gained strength and international governments began to get involved. It is estimated that 1 in 43 citizens have been killed and the majority of homes, hospitals, schools, factories and roads destroyed (Carey, 2018). The conflict continues between government forces, ISIS, and numerous secular and Islamist rebel groups (Sirin \& Rogers-Sirin, 2015). Amnesty International, the United Nations, and Human Rights Watch claim to have evidence that all parties have committed war crimes including mass murder, rape, and torture (Amnesty International, 2016b). Despite pleas from the international community to alleviate the suffering of thousands of civilians, gross human rights violations continue to take place fueling the forced movement of people and further exacerbating the refugee crisis. This conflict has resulted in a rapid deterioration of society, including the provision of health services and a massive decline in educational enrollment.

Journal of Contemporary Issues in Education, 2019, 14(1), pp. 55-70. 


\section{Mental health issues}

Conflicts throughout the world have led to widespread human rights violations including torture, detainment, violence, sexual assault, exploitation, and the deprivation of basic needs (Boothby, Strang, \& Wessells, 2006; Rutter, 2006; Stewart, McBrien, \& Ezati, 2017). The war in Syria has left 12.2 million people - including 5.6 million children — in need of humanitarian support (Sirin \& Rogers-Sirin, 2015). "Mental health is one of the most prevalent health concerns, as much of the Syrian refugee population has experienced some form of trauma, including losing family members, being subject to or witnessing violent acts, or suffering from conflict-induced physical disabilities due to the use of barrel bombs and torture" (CIC, 2015, p. 9). The prevalence of mental health conditions is particularly high among children and adolescents. The UNHCR (2013) reports that mental illness is affecting the settlement trajectory in a host country due to the trauma experienced during the conflict, the risk of detainment and violence, and the lack of resources and services within camps (Sirin \& Rogers-Sirin, 2015).

A research study on Syrian refugee children, conducted in Islahiye camp in Turkey, assessed the mental health and trauma needs of children. The summary report indicated "high levels of trauma: 79 percent had experienced a death in the family; 60 percent had seen someone get kicked, shot at, or physically hurt; and 30 percent had themselves been kicked, shot at, or physically hurt (Sirin \& Rogers-Sirin, 2015, p. 1). Prevalence of post-traumatic stress disorder (PTSD) was noted as being ten times more prevalent compared to children in other parts of the world and the rate of depressive symptoms was 44 percent (Sirin \& Rogers-Sirin, 2015). This data is consistent with a meta-analysis of research surveys conducted by Mollica (2011) with 81,866 refugees that revealed an overall mental health impact of 30.6 percent for PTSD and 30.8 percent for depression. Children and youth who are relocated to a first country of asylum such as Jordan, Lebanon, and Turkey have reported additional stressors such as discrimination, marginalization, and isolation (Sirin \& Rogers-Sirin, 2015) and relocation into a host country such as Canada also comes with persisting obstacles and challenges that can lead to uncertainty and hopelessness (Stewart, 2017). Furthermore, "the emotional trauma experienced by many refugee children may affect their cognitive, emotional, and social-development and increase their academic challenges" (Sirin \& Rogers-Sirin, 2015, p. 7).

\section{Education issues}

The school environment is crucial to the pro-social development and the acculturation of children with refugee backgrounds (Hamilton \& Moore, 2004; McBrien, 2009; Rutter, 2003; Rutter, 2006; Rutter \& Jones, 1998). There is a paucity of research that demarcates the most suitable educational context and the most appropriate support mechanisms for these students. Concomitantly, strengthening the connections among service providers, community agencies, and schools is imperative in order to provide the best and most appropriate support services and programs (MacKay \& Tavares, 2005; Rossiter \& Rossiter, 2009). Practice of education with conflict-affected individuals underscores the importance of community-driven and communitybased development (Rose \& Greeley, 2006), and the need to incorporate community needs and values into the curriculum is essential to limit tension and conflict between groups (Reimers \& Chung, 2010). With an informed and collaborative approach of conducting and sharing knowledge, the research team endeavored to provide practical strategies and concrete 
recommendations to help Syrian refugee children and youth transition successfully to life in Canada. As previous research has illustrated, when the needs of refugee youth are not addressed and when proactive support programs are not implemented, the trajectories for these youths can be unfavourable and quite often lead to marginalization and a sense of helplessness (MacNevin, 2012; Stewart, 2011).

Sirin and Rogers-Sirin (2015) report that before the conflict began in Syria, there was close to universal enrollment in both primary and secondary schools. From 2014-2015, half of the Syrian children did not attend school and in some areas, this was closer to three quarters. At present, Syria's primary enrollment is one of the lowest in the world. Even after resettlement, many children are not permitted to attend school in asylum seeking countries such as Lebanon, or Jordan and those who do attend, often do not encounter success and then leave the system. Language of instruction, discrimination, disruption in schooling, and difficulties with paying school fees, all contribute to the difficulties Syrian children encounter when trying to access education. For girls, these challenges are exacerbated as many girls experience further discrimination, isolation, and adversity. Forced marriage and sexual exploitation contribute to the overall level of trauma that girls and women experience and this makes is more likely that girls will not continue with their education.

A number of factors influence the resettlement and well-being of Syrian refugees. Understanding the historical context of Syria's conflict and how this contributes to the economic hardship and the long-term trajectory for Syrian children and youth who resettle in Canada is essential to providing the necessary settlement support for healthy development. Furthermore, increasing knowledge about the mental health and educational needs of Syrian refugees is imperative to providing the right programs, services and interventions to address the needs of Syrian children and youth. With the large influx of Syrians coming to Canada, research is needed to identify their academic and psychosocial needs in order to provide the most appropriate and supportive environment.

\section{Theoretical and Methodological Approach}

Bronfenbrenner's Bioecological Model adapted by Stewart (2011) provided an organizational structure to the investigation and insight into what systems need to be involved, and what interventions would best support Syrian refugee children. This model was used in previous research projects investigating the needs of war affected children and youth (Stewart, 2014; Stewart, Kuly, McBrien, \& Ezati, 2015). Findings from a three-year SSHRC Partnership Development Grant including researchers from Manitoba, Alberta and Newfoundland, revealed many unique and complex educational needs of refugee children (Stewart \& Martin, 2018; Martin \& Stewart, 2018; El Chaar \& Stewart, 2017). Issues related to disrupted schooling, economic difficulties, psychosocial challenges, and adjusting to a new culture and environment complicated the settlement for all refugees and newcomers (Stewart, 2017). Moreover, participants revealed that there needed to be more interaction between settlement services and educational systems and more sharing of resources and programs (Stewart, 2011). 
Bronfenbrenner and Morris (2001) believe that humans do not develop in isolation; rather, they develop in relation to the various contexts or systems to which they belong throughout their life, and are influenced by the connections and exchanges between people in these systems. Moreover, the individual and the environment have a reciprocal relationship whereby the person is both influenced by the environment and also influences that environment (Stewart, 2011). This fundamental principle was examined in this study as a means to better understand the direct and the indirect interactions that refugee children encounter in the various systems in which they live, and the challenges and successes that influence their experience settling in Canada.

The Bioecological Model (Bronfenbrenner, 1999) conceptualizes the environment "as a set of nested systems ranging from the 'micro' to the 'macro"' (p. 11). The closer most inner system, referred to as the nanosystem (Stewart, 2011) represents the closest relationships and connections to people. The microsystem represents the inner circle and environment that the person belongs to, such as a school, church, or community club. The mesosystem is the connections between the various systems, and the exosystem is the more distant system that indirectly affects the individual. The macrosystem represents the system in which all other systems exist and the overarching ideologies and beliefs of society. The final system is the chronosystem and this refers to the changes in a person over a period of time.

Bronfenbrenner's model was used as an overarching structure for the research design. With a focus on the individual student, the family system, school system and the connections between these systems, the authors were able to collect data from a multi-ecological perspective to gain a more holistic picture of the current situation related to the resettlement of Syrian refugees in Canada.

\section{Methodology}

A total of 60 semi-structured interviews were conducted consisting of 46 participants in Winnipeg and 14 participants in Calgary. Participants were newly arrived Syrians having come to Canada within the last 12 months and ranged from 11 to 35 years old. Some interviews with the youth were conducted in the participants' homes and therefore parents were also interviewed. In addition, during the winter of 2017, we conducted a one-day regional focus group in both Calgary and Winnipeg that included 30 teachers and settlement workers in Calgary and 45 settlement workers and educators in Winnipeg. Interviews took place between November 2016 and March 2017 and the youth advisory group ran for a period of 6 months between January June, 2017. In most cases, the interviews were conducted in Arabic and the transcript was later translated into English. Consent forms were provided in both languages. In some instances, the interview switched back and forth between Arabic and English, depending on the comfort of the participants and the language they chose to respond with. Interviews in both Calgary and Winnipeg were conducted by Stewart and El Chaar. The youth advisory group consisted of 10 Syrian males between the ages of 14 and 21 . The group met weekly at a settlement agency and an English teacher and Arabic speaking interpreter were the facilitators. The sessions were audio recorded, translated, and then transcribed. 
Impelling this research was the need for academics and practitioners to get a clear understanding of the psychosocial and educational needs of Canada's most recent newcomers to better plan for successful integration. The supplementary research leads directly to the development of support resources for students to provide lessons to support psychosocial healing and personal wellness. In addition, we also created professional development lessons for teachers, school leaders, and settlement workers with specific knowledge on best practices for supporting the integration of all refugees.

\section{Findings}

\section{Triple trauma effect}

Trauma can be defined as a response to a stressful experience that threatens to undermine an individual's ability to cope (Aydin, 2017; Cole, O'Brien, Gadd, Ristuccia, Wallace, \& Gregory, 2005; Ruglass \& Kendall-Tacket, 2014). Traumatic events can manifest themselves in several different ways including changing the way some individuals function cognitively, emotionally, behaviorally, and physiologically (Brahm, 2004; Ruglass \& Kendall-Tacket, 2014; UNHCR, 2015). Traumatic experiences can be an acute, one-time event, or occur continuously overtime. These experiences can be direct or indirect and occur with varying levels of intensity (Stewart \& Martin, 2018).

Participants referred to a "Triple Trauma" effect, having experienced traumatic events in Syria, then subsequently in a second country of settlement such as Lebanon, Jordan, or Turkey and again in relation to adjusting to life in Canada. Although there was often a sense of reluctance or caution toward discussing the events in Syria, we frequently heard that participants saw dead bodies on the street, experienced the loss of family and friends, and were witness to, or experienced, direct violence. Two of the older youth indicated that they were detained, but they were not forthcoming with details about what experiences they had during that time. When discussing experiences, some participants were visibly upset and we did not want to probe further into these issues and risk re-traumatization. During one group interview with 6 youth, one of the female participants became visibly upset when discussing her hopes and dreams for the future. She left the interview to take a break and then later returned. She did not want to discuss what upset her and it was not pursued further. It should be noted that one of the researchers (Stewart) is a certified counsellor with over 18 years of counselling experience with children and youth. As per the University Ethics Review Board, provisions were made to refer youth to counselling services or a support worker, if warranted.

Participants who were in a transition country, such as Lebanon, Jordan, or Turkey before coming to Canada, discussed being exploited, marginalized, and discriminated against by the host country. Many of the youth did not attend school and instead, worked for very low wages, sometimes in very dangerous conditions. Participants indicated that they were not treated fairly and often experienced hostility and anger by the Lebanese or Jordanian people. Participants noted that they were "traumatized by the treatment from people in these countries" and not treated like a human being. Some youth lived in refugee camps and others lived in informal settlement arrangements, or with friends or family. Camps were reported to be overcrowded and lacking in basic entitlements.

Journal of Contemporary Issues in Education, 2019, 14(1), pp. 55-70. 
In some instances, the process of coming to Canada took years, in others it occurred in a relatively short time with limited opportunity to prepare and plan. The settlement initiative was reported to be challenging because families were often separated and many left family members back in Syria. Almost all participants discussed how happy they were to come to Canada; however, this was couched with the feelings of uncertainty about where they would be located making them feel disrespected and powerless.

The third reference to trauma centred around settling into a new country where participants discussed challenges with learning a new language, dealing with financial constraints, feeling isolated, and problems with housing and education. Syrian youth participants, in particular, noted that they wanted to have Canadian friends and they were feeling isolated because they did not know the language or have opportunities to interact with Canadians.

We also heard participants discuss issues of survivor guilt. A Syrian mother stated, We can't forget what has passed, all the pain, and now we are trying to live a normal life but when we hear about what is happening now in Syria, we can't be happy. I cry when I eat meat because I feel bad for my family back home who has nothing to eat. I have to put my plate down and walk away.

Parents made reference to trauma, but many noted that they felt like they needed to put these experiences behind them and move on with building a life in Canada. One father said that although he is hurting inside, he has to cover up what he feels to be strong and courageous for his children.

Participants indicated that they had support at school from their friends, but none of the children or youth discussed accessing formal professional mental health assistance from a counsellor or a social worker. One participant indicated that he would see a counsellor to help with courses, but not emotional issues. He said,

Asking a question one time, like feeling like an idiot for five minutes, is better than living like an idiot forever, but I only talk to them about school work. There is nothing wrong with my mind and I don't need a psychiatrist. I can talk to my friends for support.

We also sensed a reluctance to discuss personal issues that could be related to an overlying stigma related to getting help or support. Having said this, we also sensed the overarching need to just move on. One of the young men we interviewed claimed,

Things were happening around us and my parents were really worried about us, they wanted to know why we were all singing and dancing and playing cards, so like, life goes on. We're not gonna change. That's a good attitude.

Language barriers also made talking to someone in the school difficult because translators and interpreters were not readily available.

\section{Language difficulties}

Language poses one of the main barriers to integration for newcomers in many aspects of their new lives in the country of migration. On the social level, the linguistic barrier may hinder newcomers from social interactions with peers, teachers, and the community at large. In addition, a low competency in English language may also interfere with the daily routine of students while Journal of Contemporary Issues in Education, 2019, 14(1), pp. 55-70. 
they attempt to navigate their way in a new environment. For example, a student who took the wrong bus afterschool and eventually lost his way back to his house. Not knowing which direction to go, he took one bus after the other, roaming around the city, hoping that one would take him back to his neighborhood, until he reached his house safely at 2 am. By that time, his parents were alarmed and worried to the extent that they had called the police and were searching the city for him.

With regards to academics, newcomer students had double the work, learning the English language as well as the content material. Even though many students were put in newcomer designed classes such as the LEAD (Literacy, English, and Academic Development) classes in Calgary, they were facing difficulties in learning English. Due to the influx of Syrian refugees, as it was mentioned earlier, classes were full of students speaking Arabic and the participants were mentioning in a humoristic way how they were teaching the teacher Arabic, rather than the teacher teaching them English.

In the majority of interviews "language" and difficulties learning English were the root of most problems. One high school student stated that if he knew English then all other challenges and problems would disappear. Students also expressed anger about being placed in classrooms with a majority of Arabic speaking students indicating that they would prefer to be in an Englishspeaking classroom where they would be forced to learn the language. Some participants noted that they "learn more on the street than they do in the classroom." Some students have changed schools because they prefer not to be in EAL classes.

Low English levels were also associated with feelings of powerlessness and isolation that contributed to low self-efficacy. A high school student stated, "I do not exist without the language." Another, "It is difficult, they speak to me and I say repeat, I feel I am good for nothing." A young man in the youth focus group meeting offered, "All the problems and challenges I have would be gone if I had English." Immediately after hearing this statement another boy from the focus group asked the researchers, "So what are you going to do now to fix this problem for us?" Speaking for the group, he asserted that they want more opportunity to meet Canadian kids and to learn English that is not taught in the classroom.

Based on these statements, we decided to pilot a program that partnered one Canadian student from a first-year Faculty of Education course at The University of Winnipeg, called "Service Learning," together with one Syrian student from the Thursday youth Syrian boys' advisory group we started a couple months earlier. We held a group meeting and then partnered the students up randomly by pulling names from a hat. The students were given a modest spending budget and were to meet each other one evening a week. The only goal of the program was to help teach the Syrian students English by engaging in shared activities. The students were not to go in a group, instead they were to go out one-to-one and take part in various activities in the neighbourhood. We quickly realized that the language barriers between the two students would pose additional challenges related to reading texts and arranging for outings. The facilitator started to organize some group activities such as dancing, going out for food, curling, and watching hockey games to assist with getting kids together. 
In hindsight, we would incorporate more adult involvement to help arrange the meetings and outings, but for the most part, students did get together and did some fun activities and they had an opportunity for reciprocal learning about culture, language, and customs that would not have been possible without the program. While we did not assess the language acquisition, we were able to informally observe that there was learning on both sides (Canadians learning Arabic and Syrians learning English) and shared interests between the students. This was only a small pilot program; however, we will pursue a similar program in the future and provide more formal assessment and evaluative measures.

\section{Educational gaps}

From the educational point of view, some students have missed more than four years of education due to their displacement making it challenging for them to start at a much higher level than their last attended class. In addition, students' expectations differed from what they were offered in Canada; for example, one of the students who left Syria when he was in grade four had worked for four years and once in Canada he was placed in grade eight. He said, "I thought they will teach us the material that we missed, but I was surprised to be placed in grade eight." The students had to cope with two aspects at the same time: learning the language and learning the material they had missed during the years of displacement.

On the social level, most of the students were working prior to coming to Canada, some starting at the age of 10 or 11 . The nature of work they were doing was either in agriculture, carpentry, butchery, baking, or even in the supermarkets bagging groceries. These boys became men at a young age, earning income for the family and providing support to younger children. Some of these students had to work unofficially as they indicated if they were found to be working, they would be deported. Coming to Canada, they were asked to put such a role to the side and go "back" to the social role of being a dependent member of the family. Such a change of social roles, coupled with the frustration students were facing due to their educational gaps, led some of them to opt out of schools to join the workforce. The challenge associated with working before finishing high school, is that such a shift might place the newly arrived refugees in survival, or seasonal jobs which are temporary in nature, and provide minimum earning potential.

Educational gaps are a considerable problem for the 14-18 demographic. Many of these students were working in Lebanon or Jordan and were not permitted to go to school. Sirin and RogersSirin (2015) report that "the influx of Syrian children has stretched educational resources in Lebanon, Jordan, and Turkey" (p. 9) and the majority of Syrian children are not in school. After resettlement, these students have large gaps in their learning and teachers fear that they will "age out" of the system without having the skills or language ability required to go on to additional training, schooling, or to secure employment. The students who have been carpenters, bakers, roofers, or helped with a family business, were unable to find jobs they can do with their limited English and no formal training.

\section{Teachers feel unprepared}

Throughout the study, it was indicated that there is a general insufficiency of knowledge regarding the history of Syria as well as the ongoing conflict that students' have experienced in their home country. This is further complicated when adding the knowledge that not all student 
experiences will be the same. As mentioned previously, some students will have had their lives significantly disrupted and will have lost loved ones, while others will have experienced extreme violence first hand. Research participants were consistent in suggesting that understanding the realities of where the students were coming from would be helpful in gaining a better starting point for building relationships with students and being better able to recognize mental health symptoms. One teacher asserts "the triggers are very essential for us to know," revealing the need for educators to create trauma-sensitive spaces conscious of potential triggers such as loud noises or violent imagery. This is further demonstrated by interviewees revealing that it is not uncommon for children to experience inappropriate responses to behaviour that could be potentially misunderstood, such as unknown cultural differences or a child becoming aggressive out of fear for personal safety. In general, teachers and school leaders indicated that more training was needed to give them the background for how best to respond to children who have experienced trauma and how to best support students learning English while also teaching ageappropriate curriculum with limited or no resources.

Teachers also revealed a lack of training in terms of basic counselling skills exacerbating feelings of inadequacy when confronted with difficult stories and circumstances disclosed by their students. It should be mentioned that this is not to suggest that teachers need to be the provider of all services to all students, but that they feel the need to have some level of competency when faced with the disclosure of difficult or sensitive information, specifically to keep from causing further or unnecessary harm. It was suggested that gaining basic knowledge toward understanding the impact of grief and loss would be beneficial in providing appropriate support and meeting the needs of individuals who have been affected by the loss and separation of loved ones.

Further complicating the ability to assist students were expressed concerns around not knowing the resources and services that are available in the community for added support. While some schools demonstrated a great deal of effort in creating partnerships with outside agencies and a more holistic approach to providing students with necessary resources, many teachers expressed both a lack of awareness of existing programs, and a lack of time available to visit or research known institutions, adding to the stress and feelings of isolation in trying to meet students' academic, social, and mental health needs.

\section{Hopes and dreams}

In each interview, we asked students what they hoped for or dreamed about for their future. Without any hesitation, and often before we finished the question, the response was "Syria." Students just want to go home - back to Syria, but as it existed before the war. Many youth long to have their old way of life and to have their friends together. One student comments, "I don't want to go back to see all the holes - I want to go back to see my friends, but they are all gone." We noted a tremendous sense of loss and longing to a return to life the way it was. Students discussed the jobs they aspired to in the future, but they were also quick to state that without English they had no hope of getting into schools to prepare for these jobs. Students reflected that life can be hard in some schools as they contend with discrimination and racism, however they also stated that, for the most part, students have just left them alone. This was also found to be frustrating as they really wanted to have Canadian friends. 
We posed the same question to parents and the majority of them said they do not have any dreams for their future - their dreams are for their children to have a better life. One father states, "It is too late for me...I do not have any hope for a future - my dreams are for my children. That is all I want. That is why we came here." Parents also reported a sense of loss as many had fulltime employment in Syria, were connected to their communities, and felt a sense of purpose that they no longer had. In Canada, it is a struggle to learn the language, gain employment, and support their children as they too adjust to life in a new country. Many parents felt that they did not have time to adequately help their children because they were struggling with their own issues of adjustment, loss, and learning English or working multiple jobs to provide for their children.

Most of the Syrians have lost a way of life, their friends, and community. Coming to Canada represents a new start and hope for a better future. Participants have sacrificed a lot, but they express enormous gratitude to the government for bringing them to Canada. Most are determined to learn English with a sense of urgency and immediacy and they are eager to become fully engaged members of the community and contributors to the Canadian economy. The majority of participants are looking forward to becoming Canadian citizens and giving back to society. While we did encounter some parents who did not want to work, for the most part this was because of a difficulty in finding childcare and the cost of putting multiple children in daycare was more than they would make in full-time employment.

\section{Conclusion}

This research set out to uncover the integration and settlement needs and challenges for Syrian children and youth in Winnipeg and Calgary. The needs of Syrian refugee youth are complex, multi-faceted, and unique from other refugee groups. Many of the Syrians have lost their entire livelihood. Prior to the conflict, the majority of parents worked, some families held businesses or farmed, children were in school, and family members were together. The war took this life away. For those who were displaced in Lebanon, Jordan or Turkey, they were further stripped of their sense of culture and belonging and many discussed further marginalization. Other refugees coming to Canada, such as those coming from sub-Saharan Africa, have lived an average of 20 or more years in refugee camp situations with little or no hope for a better future (UNHCR, 2016). Some have only lived in times of conflict while others have been born in camps with no access to education and they have been denied basic human entitlements.

Most of the Syrian refugees longed to return home and gain back their way of life and level of affluence, while this was not found to be as prevalent in other studies with refugee groups now living in Canada (Stewart, 2011). The politicization of the movement of Syrians also figured more prominently in Canadian society, and as such, we saw more media attention to the plight of the Syrians and more widespread mobilization of settlement services and community initiatives to help the Syrians. As a corollary to this, we also witnessed some resentment within the refugee communities as there was a perception that the Syrians were given preferential treatment by the Canadian government at the expense of helping other refugees. There is a lot at stake when there is intense media attention on an issue, as such, there appeared to be more of a commitment to Journal of Contemporary Issues in Education, 2019, 14(1), pp. 55-70. 
ensuring that the Syrian movement was successful. The references to trauma and the sense of loss were paramount in the Syrian interviews.

Because of these aforementioned factors, there is a need for more targeted research to better understand these issues. Moreover, the specific long-term settlement and educational needs of Syrian refugee children and youth in Canada is difficult to predict without additional research that spans over a longer period of time. Our research occurred within a relatively short period of time after the new arrivals from Syria came to Canada. As government subsidies diminish and programs, such as language classes disappear, more complications and difficulties related to settlement and integration may emerge. Conversely, as best practices are reported, successful support mechanisms are recounted, and lessons are learned, we will gain valuable insights and understandings about how to best support families from refugee backgrounds.

This study identified the school as a primary source for supporting children and youth and the only place where hopes and dreams can become a reality. The school is a safe and protected place, but this does not mean that memories of war and violence can be forgotten. Teachers and settlement workers need to understand more about the refugee experience and they need to know how to provide culturally-relevant support to children who have experienced trauma. Education is the pathway towards learning English, acquiring additional training, and gaining and maintaining meaningful employment. As such, we need to collectively strive to engage students in learning, provide the psychosocial support to assist with their well-being, and ensure they have the opportunity to be successful.

Settlement efforts must have a coordinated approach between educational institutions, youth and their families, settlement agencies, and community organizations. The findings from this study indicate that Canadians and Canadian service providers also have a major role in supporting the successful integration of refugees. Integration requires the collaborative efforts of all members from all ecological systems. Cultural support workers, cultural brokers, and community liaison personnel are also paramount to bridging the school to families and community agencies.

The research was able to highlight needs and essential gaps in program and service provision for recently arrived refugees. It is hoped that the findings will encourage the continuation of support for identified best practices and the allocation of funding and resources to address trauma, interrupted schooling, separation and loss, racism and discrimination, educational challenges, mental health support, and isolation associated with resettlement.

\section{Acknowledgement}

This research was supported by the Social Sciences and Humanities Research Council of Canada, Mitacs, and CERIC. 


\section{References}

Al Jazeera. (2017a). The boy who started the Syrian civil war. Retrieved from http://www.aljazeera.com/programmes/specialseries/2017/02/boy-started-syrian-war170208093451538.html

Al Jazeera. (2017b). Syria's civil war explained from the beginning. Retrieved from http://www.aljazeera.com/news/2016/05/syria-civil-war-explained160505084119966.html

Amnesty International. (2015). The global refugee crisis: A conspiracy of neglect. Retrieved from https://www.amnesty.org/en/documents/pol40/1796/2015/en/

Amnesty International. (2016). Tackling the global refugee crisis: From shrinking to sharing responsibility. Retrieved from https://www.amnesty.org/en /documents/pol40/4905/2016/en/

Aydin, C. (2017). How to forget the unforgettable? On collective trauma, cultural identity, and mnemotechnologies. Identity: An International Journal of Theory and Research, 17(3), 125-137. http://dx.doi.org/10.1080/15283488.2017.1340160

BBC. (2017). Why is there a war in Syria? Retrieved from http://www.bbc.com/news/world/middle-east-35806229

Boothby, N., Strang, A., \& Wessells, M. (Eds.). (2006). A world turned upside down: Social ecological approaches to children in war zones. Bloomfield, CT: Kumarian.

Brahm, E. (2004, January). Trauma healing. Beyond Intractability. Retrieved from http://www.beyondintractability.org/essay/trauma-healing

Bronfenbrenner, U. (1999). Environments in developmental perspective: Theoretical and operational models. In S. Friedman \& T. Wachs (Eds.), Measuring environment across the life span: Emerging methods and concepts (pp. 3-28). Washington, DC: American Psychological Association.

Bronfenbrenner, U. (2001). The bioecological theory of human development. In N. J. Smelser \& P. B. Baltes (Eds.), International encyclopedia of the social and behavioural sciences, vol. 10. (pp. 6963-6970). New York, NY: Elsevier.

Bronfenbrenner, U., \& Morris, P. (1999). The ecology of the developmental process. In W. Damon \& R. Lerner (Eds.), Handbook of child psychology (5 $5^{\text {th }}$ ed.) (pp. 793-828). New York, NY: John Wiley and Sons.

Carey, G. (2018, December). Syria 's civil war. Retrieved from https://www.bloomberg.com/quicktake/syrias-civil-war

Citizenship and Immigration Canada (CIC) (2015). Population profile: Syrian refugees. Retrieved from http://www.cpa.ca/docs/File/Cultural/EN\%20Syrian\%20Population\%20Profile.pdf

Cole, S. F., O’Brien, J. G., Gadd, M. G., Ristuccia, J., Wallace D. L., \& Gregory, M. (2005). Helping traumatized children learn: Supportive school environments for children traumatized by family violence. Massachusetts Advocates for Children. Retrieved from https://traumasensitiveschools.org/ wp-content/ uploads/2013/06/Helping -Traumatized-Children-Learn.pdf

El Chaar, D., \& Stewart, J. (2017). Building welcoming communities and schools. Werklund School of Education. Retrieved from http://werklund.ucalgary.ca/node/3999

Journal of Contemporary Issues in Education, 2019, 14(1), pp. 55-70. 
Hamilton, R. \& Moore, D. (Eds.). (2004). Educational interventions for refugee children. New York: RoutledgeFalmer.

Human Rights Watch. (2017) Syria: Events of 2016. Retrieved from https:/www.hrw.org/worldreport/2017/country-chapters/syria

Immigration, Refugees and Citizenship Canada (IRCC) (2017a). Welcome refugees: Key figures. Retrieved from http:/www.cic.gc.ca/english/refugees/welcome/milestones.asp

Immigration, Refugees and Citizenship Canada (IRCC) (2017b). Canada admissions of resettled refugees by province/territory of intended destination, gender, age group and immigration category- January 2015-December 2017. Retrieved from https://open.canada.ca/data/en/dataset/4a1b260a-7ac4-4985-80a0-603bfe4aec11

Lahav, G. (2016). The global challenge of the refugee exodus. Current History, 115, (777), $10-$ 16.

Martin, L., \& Stewart, J. (Winter 2018). Bridging two worlds: Supporting newcomer and refugee youth. Cognica,50(1), pp 12-15.

MacKay, T. \& Tavares, T. (2005, October 20). Building hope: Appropriate programming for adolescent and young adult newcomers of war-affected backgrounds and Manitoba schools. Winnipeg, MB: Manitoba Education, Citizenship and Youth.

MacNevin, J. (2012). Learning the way: Teaching and learning with and for youth from refugee backgrounds in Prince Edward Island. Canadian Journal of Education, 35(3), 48-63.

McBrien, J. L. (2009). Beyond survival: School related experiences of adolescent refugee girls and their relationship to motivation and academic success. In G. Wiggan \& $\mathrm{C}$. Hutchinson (Eds.), Global issues in education: Pedagogy, policy, school practices and the minority experience (pp. 294-330). Lanham, MD: Roman \& Littlefield.

Mollica, R. (2011). Global mental health: trauma and recovery: A companion guide for field and clinical care of traumatized people worldwide. (pp. 13-43). Harvard Program in Refugee Trauma.

Reimers, R.M., \& Chung, C.K (2010) Education for human rights in times of conflict. Development 53(4), 504-510. http://dx.doi.org/10.1057/dev.2010.82

Rose, D., \& Charette, A. (2017). Challenges and policy implications in finding housing for refugee newcomers: Learning from the Syrian resettlement operation. Canadian Diversity, 14(3), 35-38.

Rose, P., \& Greeley, M. (2006). Education in fragile states: Capturing lessons and identifying good practice. University of Sussex: Centre for International Education. Retrieved from http://www.gsdrc.org/go/display\&type=Document\&id=2599

Rossiter, M. J., \& Rossiter, K. R. (2009). PMC working paper series immigrant youth and crime: Stakeholder perspectives on risk and protective factors. Retrieved from http://pcerii.metropolis.net/WorkingPapers/WP0209.pdf

Ruglass, L., \& Kendall-Tackett, K. (2014). Psychology of trauma 101. New York, NY: Springer. http://dx.doi.org/10.1891/9780826196699

Rutter, J. (2003). Supporting refugee children in 21st century Britain. Stoke on Trent, UK: Trentham Books.

Rutter, J. (2006). Refugee children in the UK. Berkshire, England: Open University Press. Rutter, J. \& Jones, C. (Eds.). (1998). Refugee education: Mapping the field. Stoke on Trent, UK: Trentham Books.

Journal of Contemporary Issues in Education, 2019, 14(1), pp. 55-70. 
Sirin, S. R., \& Rogers-Sirin, L. (2015). The educational and mental health needs of Syrian refugee children. Washington, DC: Migration Policy Institute. Retrieved from https://www.migrationpolicy.org/research/educational-and-mental-health-needs-syrianrefugee-children

Stewart, J. (2017, March 14). Creating a culture of care and compassion for refugee students: A state of nhân đạo. Education Canada, 57(1). https://www.edcan.ca/articles/a-culture-ofcare-and-compassion-for-refugee-students/

Stewart, J. (2014). Education for peace and sustainable development in conflict affected countries. In F. Deer, T. Falkenberg, B. McMillan, \& L. Sims (Eds.), Sustainable wellbeing: Concepts, issues, and educational practices (pp.189-205). Winnipeg, MB: ESWB Press. Retrieved from www.ESWB-Press.

Stewart, J. (2011). Supporting refugee children: Strategies for educators. Toronto, ON: University of Toronto Press Higher Education.

Stewart, J., Kuly, M., Ezati, B., \& McBrien, J. L. (2015). The importance of storytelling in post-conflict states. In L. Finley, J. Connors \& B. Wien (Eds.), Teaching peace through popular culture. Charlotte, NC: Information Age.

Stewart, J., \& Martin, L. (2018). Bridging two worlds: Supporting newcomer and refugee youth. Toronto, ON: Canadian Education Research Institute for Counselling. www.ceric/twoworlds

Stewart, J., McBrien, J., \& Ezati, B. (2016). Rebuilding, healing and transforming: Innovativeapproaches and promising strategies for children affected by war. International Journal of Talent Development and Creativity,4(1), 121-136.

United Nations High Commissioner for Refugees (2017). Figures at a glance. Retrieved from http://www.unhcr.org/figures-at-a-glance.html

United Nations High Commissioner for Refugees. (2016) Global trends: Forced displacement in 2015. Retrieved from http://www.unhcr.org/statistics/unhcrstats/576408cd7/unhcrglobal-trends-2015.html

United Nations High Commissioner for Refugees (2015). Culture, context and the mental health and psychosocial wellbeing of Syrians: A review for mental health and psychosocial support staff working with Syrians affected by armed conflict. Retrieved from http://www.unhcr.org/55f6b90f9.pdf

United Nations High Commissioner for Refugees. (2013). At a glance: Health data for Syrian refugees; Iraq, Jordan and Lebanon. Retrieved from https://data.unhcr.org/syrianrefugees/download.php?id=5635 